\title{
AQUARELA SUSTENTÁVEL: IMAGENS REPRESENTATIVAS DA CONCEPÇÃO DE SUSTENTABILIDADE A PARTIR DE DESENHOS DE CRIANÇAS E ADOLESCENTES PESSOENSES
}

Data de submissão: 14/05/2018 Aceite: $27 / 09 / 2018$

Ana Lúcia de Araújo Lima Coelho ${ }^{1}$ Helaine Cristine Carneiro dos Santos ${ }^{2}$ Arthur William Pereira da Silva ${ }^{3}$ Christiano Coelho ${ }^{4}$ Brenda Nathália Fernandes Oliveira ${ }^{5}$

\section{RESUMO}

Partindo-se do fato de que as crianças e adolescentes de hoje serão as gestoras das futuras sociedades, se faz relevante para a viabilidade de qualquer forma de sustentabilidade futura entender como estes indivíduos concebem essa maneira de administrar os recursos disponíveis, para assim possibilitar o alinhamento dessas formas de conceber com os princípios desta nova possibilidade de gerir, por meio da educação para a sustentabilidade. Dessa forma, o objetivo deste trabalho foi analisar as concepções de sustentabilidade de alunos do Ensino Fundamental I e II de uma escola particular localizada na cidade de João Pessoa a partir de desenhos. O estudo possui uma abordagem qualitativa e lança mão do método da análise fenomenográfica de desenhos. Os resultados revelam que os alunos do ensino fundamental I, em sua maioria, possuem uma concepção voltada apenas para o pilar ambiental e em menor grau para o social, enquanto os alunos do ensino fundamental II abordam em seus desenhos concepções mais amplas, envolvendo tanto elementos ambientais e sociais como econômicos, resultados estes que servem como evidência preliminar da eficácia das ações de educação para sustentabilidade na escola investigada. Entretanto não a comprovam, ensejando para tanto mais profunda investigação.

Palavras-chave: Educação para Sustentabilidade; Desenhos; Crianças; Adolescentes; Concepções.

\footnotetext{
1 Doutora em Administração e Turismo pela Universidade do Vale do Itajaí - UNIVALI com período sanduíche na Universidad Complutense de Madrid; Mestre em Administração pela Universidade Federal de Santa Catarina - UFSC; Graduada em Ciências Contábeis pela UFSC. E-mail:alalcoelho@gmail.com

2 Mestre em Administração pela Universidade Federal da Paraíba - UFPB; Graduada em Administração pela Universidade Federal Rural de Pernambuco - UFRPE. E-mail: helainecristine@hotmail.com

3 Doutorando em Administração pela Universidade Potiguar - UnP; Mestre em Administração pela Universidade Federal da Paraíba UFPB; Mestre em Ambiente, Tecnologia e Sociedade pela Universidade Federal Rural do Semi-Árido - UFERSA; Especialista em Gestão empresarial pela UnP; e graduado em Administração de Empresas pela UnP. E-mail: arthurwilliamadm@hotmail.com 4 Doutorando em Ciências Ambientais pela Universidade Federal da Paraíba (UFPB). Mestre em Contabilidade (2010) e Graduado em Ciências Contábeis (2002), pela Universidade Federal de Santa Catarina (UFSC). E-mail: floripacoelho@gmail.com

5 Especialista em Saúde Pública pela Universidade Norte do Paraná - UNOPAR; Graduada em Nutrição pela Universidade Potiguar UnP. E-mail: nutricionistabrendanathalia@gmail.com
} 


\section{PRIMEIROS TRAÇOS: [...] NUMA FOLHA QUALQUER EU DESENHO (FABRÍCIO ET AL., 1983)}

Nas últimas décadas, o conceito de sustentabilidade vem se intensificando cada vez mais. Essa realidade se deu, provavelmente, pelo fato de vivermos em uma economia capitalista, social e ambientalmente degradante a longo prazo (BARCELOS, 2008).

Atualmente, de acordo com a área e os objetivos dos estudos desenvolvidos, existem várias interpretações sobre o conceito de sustentabilidade, porém todos eles, de alguma forma, concordam que este conceito norteia a base da abordagem transdisciplinar, percorrendo diversas áreas (MIKHAILOVA, 2004). Para Melo (2008), sustentabilidade é um compromisso com as gerações futuras. Leff (2001) abrange o conceito ao defender que a sustentabilidade limita a racionalidade econômica, abrindo oportunidade para que outros valores como justiça social e responsabilidade com as próximas gerações entrem em foco.

Lopes e Tenório (2006) defendem que a educação é fundamental em todos os processos da constituição da cidadania, sendo esta, um ponto crucial inclusive para o que chamamos hoje de educação para sustentabilidade (EPS). Esse entendimento permite perceber que só se muda pessoas por meio do conhecimento, e o conhecimento só é possível por meio da educação. Trata-se de um pressuposto bem conhecido do educador, pedagogo e filósofo, Paulo Freire: "A educação não transforma o mundo. Educação muda pessoas. Pessoas transformam o mundo" (FREIRE, 1996, p. 29). Nesse sentido, observa-se a necessidade de realizar reflexões sobre como seria uma educação pautada na sustentabilidade, e como a gestão das escolas atua diante desta nova realidade. Para isso, é preciso entender o que é educação para sustentabilidade e qual papel das escolas neste contexto.

Segundo Moura (2016), já há algum tempo a área de educação vem recebendo grande atenção e influência da administração, isso porque os modelos de gestão escolar estão cada vez mais presentes no ambiente educacional. Vários autores iniciaram os estudos sobre as práticas administrativas na gestão das escolas, fomentando debates sobre como esta gestão pode contribuir para estas instituições de ensino e (trans) formar as crianças e adolescentes em cidadãos e profissionais mais atuantes frente às questões sociais (LEÃO, 1945; TEIXEIRA, 1961; RIBEIRO, 1986; LOURENÇO FILHO, 2007).

Os estudos da administração devem transpor as fronteiras organizacionais, ou seja, devem sair da teoria e das paredes empresariais e alcançar contextos mais amplos, interferindo de forma positiva na formação de uma sociedade mais ativa e engajada na busca por um mundo melhor.

As Diretrizes Curriculares Nacionais do Curso de Graduação em Administração explicitam este comprometimento por meio das competências e habilidades que o administrador deve exercer (BRASIL, 2005). Dessa forma, o administrador atua como agente de mudança social. Azevedo e Grave (2011) enfatizam que este compromisso vai além de uma simples existência qualquer, mas está comprometido com a existência em que o homem é capaz de viver bem, em um mundo melhor. Para que se alcance essa tão desejada melhoria é preciso viver de forma sustentável, atendendo às necessidades do presente sem comprometer as gerações futuras. Esse caminho pode ser percorrido diante de uma educação voltada à sustentabilidade. Para isso, é preciso entender o que é EPS e qual o seu papel nas escolas.

A EPS é um conceito relativamente novo, surgido da necessidade de estreitar a relação entre desenvolvimento e educação (MOCHIZUKI; FADEEVA, 2010). Trata-se de um processo de aprendizagem transformadora, em que os sujeitos, sejam alunos, professores ou qualquer pessoa interessada no tema, desenvolvem uma nova forma de pensar e de agir, visando ao alcance 
de uma prosperidade econômica aliada à diversidade ecológica e um comportamento responsável da sociedade (DUBEY; GUNASEKARAN; DESHPANDE, 2017).

Já a escola, dentro do contexto da EPS, assume o papel de equilibrar uma função sistêmica de preparar cidadãos tanto para desenvolver suas qualidades, como para a vida em sociedade, ao mesmo tempo em que exercita sua função crítica e busca soluções para os problemas locais (PIRES, 2007). Nesse contexto, pode-se enxergar a escola como uma ferramenta da prática cidadã, aliada à condição em que o aluno tem de se posicionar e manifestar sua opinião como indivíduo, membro de uma sociedade, promovendo debates, construindo e compartilhando conhecimento (PALMA; ALVES; SILVA, 2013).

Diante dessa conjuntura é imprescindível que esta consciência seja incutida o quanto antes, ainda na infância, principalmente no ensino fundamental, embora todos os níveis sócio-cultural, econômico e educacional precisem provocar essas reflexões, transformando as crianças e adolescentes de hoje em adultos mais responsáveis e engajados no que diz respeito à sustentabilidade.

Este trabalho utiliza representações gráficas (desenhos) na busca do que estas crianças e adolescentes entendem por sustentabilidade.

O desenho pode ser considerado uma expressão gráfica, uma forma de comunicação representada pelo homem desde a época da pré-história. Por meio das marcas e registros desenhados nas paredes das cavernas, o homem criou símbolos e começou a escrever a sua história (DERDYK, 1990). Os desenhos são uma forma lúdica das crianças representarem suas concepções a respeito de diversos temas, estimulando a criatividade e a imaginação dos pequenos. Para Moreira (1984), o desenho da criança é a primeira forma que ela encontra de se expressar, iniciada antes mesmo de ela dominar a leitura e a escrita. Nesta mesma direção, Junqueira Filho $(2005$, p. 54) defende que a criança

\begin{abstract}
aprende ainda sobre sua própria humanidade, na medida em que, ao desenhar, a criança está realizando - reafirmando e atualizando - algo ancestral de sua humanidade: a capacidade e a necessidade dos seres humanos de se deixarem em marcas. Foram os seres humanos que inventaram o desenho e, ao fazê-lo, puderam dizer algo de si por meio de imagens, puderam se ver representados graficamente em aspectos de sua humanidade; deixaram-se em marcas que contribuíram para a produção de sua humanidade, de sua história; que contribuíram para a demarcação, comunicação e significação de sua passagem pela vida, pelo planeta Terra, pelo mundo.
\end{abstract}

Na infância, o desenho constitui uma linguagem universal, compreendida por todas as culturas e capaz de expressar pensamentos e sentimentos, envolvendo aspectos cognitivos e emotivos (DERDYK, 2004). Klein (1975/1997) ressalta que

as crianças não conseguem fazer associações da mesma maneira que os adultos. [...] provavelmente as crianças não podem fazer isso, não porque não tenham a capacidade de traduzir seu pensamento em palavras (isso só se aplicaria, até certo ponto, a crianças muito pequenas), mas porque a ansiedade resiste a associações verbais. (KLEIN, 1975/1997, p. 176).

De acordo com o Referencial Curricular Nacional para a Educação Infantil (BRASIL, 1998), o desenho como linguagem sugere signos históricos e sociais que permitem ao homem significar o seu mundo. Sendo assim, a Educação Fundamental é um espaço para o viver da infância e adolescência que promove a assimilação de diferentes linguagens e manifestações expressivas, dentre elas, o desenho, signo dotado de concepções.

Dessa forma, o objetivo deste trabalho foi analisar as concepções de sustentabilidade de alunos do Ensino Fundamental I e II de uma escola particular localizada na cidade de João Pes- 
soa/Paraíba a partir de desenhos. A escolha do ensino fundamental, correspondente às séries do 10 ao 9o ano com idade média (IM) de 6 a 14 anos, ocorreu devido a este período de aprendizado ser a fase de formação inicial dos alunos, ou seja, é a época em que esses alunos adquirem seus princípios e valores; relacionam seus conhecimentos, experiências e vivências com a realidade ao seu entorno. Além disso, nesta fase, as crianças e adolescentes não apenas internalizam os significados e valores do mundo, mas também contribuem para produção e mudança deste, (re) produzindo e (re)criando comportamentos de maneira individual e coletiva que o acompanham por toda a vida (NEVES et al., 2017).

Por fim, é importante apresentar uma rápida reflexão sobre a contribuição da presente pesquisa para a área de administração. A administração é a ciência que visa levar as organizações à consecução dos seus objetivos, isto por meio da gestão eficiente e eficaz dos recursos disponíveis (ETZIONI, 1984; SCHEIN, 1982). Por muitos séculos, isso se deu em um ambiente em que pouco se pensava nos impactos da utilização não planejada desses recursos ao meio ambiente e à sociedade. Porém, desde o fim do século XX, a comunidade mundial vem chegando a um consenso de que se faz urgente uma mudança drástica dessa forma de utilização não planejada e impensada dos recursos naturais por parte das organizações, tendo em vista a preservação desses recursos para suprir também as necessidades das futuras gerações, e assim promover o desenvolvimento sustentável (MACÊDO; OLIVEIRA, 2005; JACOBI, 2006; NASCIMENTO; CURI, 2013).

Quando se entende a sustentabilidade e o desenvolvimento sustentável como sendo a administração sustentável dos recursos financeiros, naturais e sociais disponíveis, fica clara a ligação e relevância desta pesquisa para a área da administração, tendo em vista que a partir desse entendimento, por meio desta pesquisa se busca analisar as concepções de administração sustentável de estudantes do ensino fundamental.

Levando-se em conta que as "crianças do agora" serão as "gestoras do por vir", se faz relevante para a administração sustentável entender como estas concebem essa nova forma de administrar os recursos disponíveis, para assim possibilitar o alinhamento dessas concepções com os princípios desta nova forma de gerir, por meio da EPS.

\section{SUSTENTABILIDADE E SEUS CONTORNOS: [...] COM CIN- CO OU SEIS RETAS É FÁCIL FAZER (FABRÍCIO ET AL., 1983)}

Uma das características que emergem da natureza interdisciplinar do conceito de sustentabilidade é a pluralidade de entendimentos existentes quanto ao seu conceito. (LANKOSKI, 2016). A esse respeito, Dovers e Handmer (1992) afirmam que a sustentabilidade é um conceito que tem influenciado cada vez mais a política de desenvolvimento nas últimas duas décadas, mas o conceito permanece mal definido. Dessa forma, é sabido que existe uma infinidade de formas de entender o que é sustentabilidade.

Inicialmente o conceito de sustentabilidade estava atrelado diretamente à preservação ambiental (MELO NETO; BRENNAND, 2004). De acordo com os autores, os projetos sustentáveis centravam-se apenas em diminuir os riscos ambientais, mas com o tempo, surgiram vários outros conceitos. Na sua etimologia, sustentabilidade, significa tudo o que se conserva, que se mantém, que se renova ao longo do tempo. Em seus estudos, Bermejo (2001) constatou haver mais de 200 conceitos sobre sustentabilidade, o que até hoje gera várias discussões a respeito da definição do termo.

No intuito de facilitar a sua apresentação, surgem dois grandes grupos no que se refere ao número de aspectos ou vertentes que compõem o escopo da sustentabilidade, a saber: primeiramente, aqueles que abordam o tema a partir dos três aspectos básicos da sustentabilidade, 
mais conhecidos como tripé da sustentabilidade (Figura 1), que são os aspectos social, econômico e ambiental, defendendo que ao equilibrar a tomada de decisões levando em consideração princípios sustentáveis relevantes dessas três vertentes, os indivíduos, as organizações e a sociedade podem alcançar a sustentabilidade, entre esses autores encontram-se: Elkington (1997); Jacobi (2003); Cavalcanti (1998); Jones, Selby e Sterling (2010).

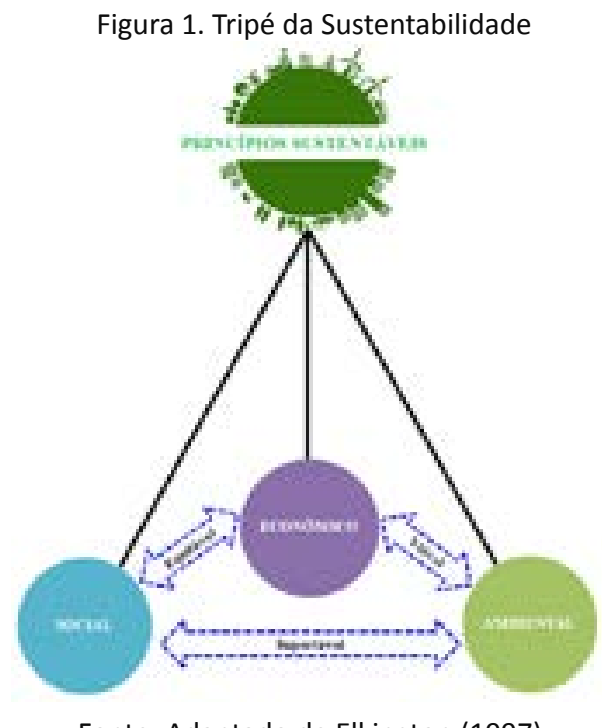

Fonte: Adaptado de Elkington (1997).

E um segundo grupo, que também considera como condição essencial o equilíbrio entre os três aspectos básicos para o alcance da sustentabilidade, porém propõe vertentes adicionais, além das três básicas, que também consideram relevantes para a consecução da sustentabilidade. Esses aspectos adicionais tanto representam pormenorizações dos três aspectos principais, como dimensões ou aspectos extras, como os propostos por Sachs (2002) que ampliou o leque de dimensões da sua abordagem, passando a considerar as oito dimensões seguintes: social, cultural, ecológica, ambiental, territorial, econômica, política nacional, e a política internacional. Ou ainda Lopes e Tenório (2006) que acrescentaram a dimensão educacional ao tripé da sustentabilidade.

Dessa forma, devido a sustentabilidade não possuir um conceito único e consensual, como é defendido por Huckle (2014):

Ela assume significados distintos em diferentes ideologias e programas apoiados pelos mais variados tipos de conhecimentos, valores e filosofias políticas. Seus significados são contestados e uma das funções-chave da educação para a sustentabilidade é ajudar as pessoas a refletir e agir sobre esses significados, para, a partir disso, perceber futuros alternativos de maneiras mais informadas e democráticas (HUCKLE, 2014, p. 18).

O que advém de sua natureza interdisciplinar de acordo com Ratiu e Anderson (2015), nessa pesquisa foi adotada, a fim de embasar a análise dos dados, o conceito de sustentabilidade como o processo de tomada de decisões embasado nas dimensões econômica, social e ambiental, conceito este defendido por autores como Elkington (1997); Jacobi (2003); Cavalcanti (1998); Jones, Selby e Sterling (2010). A escolha dessa linha de pensamento em detrimento de uma linha de pensamento mais complexa, ou de um entendimento de sustentabilidade que comporte mais vertentes ou dimensões, como o entendimento defendido por Sachs (2002) ou Lopes e Tenório (2006), se deu pois os dados analisados neste trabalho consistem em desenhos produzidos por crianças e 
adolescentes que ainda cursam o ensino fundamental I e II, sendo a compreensão da maior parte das dimensões extras propostas por estes últimos autores de difícil acesso nesse nível escolar.

A partir desse entendimento, a próxima seção abordará o tema da EPS, por acreditar que mediante uma consciência crítica, a sociedade seja capaz de gerar cidadãos verdadeiramente capazes de mudar o mundo (SPRINGETT, 2005; GADOTTI, 2008; SAMUELSSON; KAGA, 2008; JICKLING, 2009; SARTORI; LATRÔNICO; CAMPOS, 2014; GRISWOLD, 2017; DUBEY; GUNASEKARAN; DESHPANDE, 2017)

\section{EDUCAÇÃO PARA SUSTENTABILIDADE: (RE)DESE- NHANDO UMA (NOVA) SOCIEDADE - [...] SE UM PINGUI- NHO DE TINTA CAI NUM PEDACINHO AZUL DO PAPEL (FABRÍCIO ET AL., 1983)}

Lopes e Tenório (2006) propõem a educação como uma quarta dimensão da sustentabilidade e do desenvolvimento sustentável, recebendo esta dimensão a importante e estratégica missão de difundir os princípios e fundamentos dessa nova visão e desse novo modelo de desenvolvimento por toda a sociedade, de forma a prover os indivíduos de uma nova forma de ver a si mesmo e o mundo ao seu redor.

Para os autores supracitados, a única forma de promover uma mudança tão drástica na forma como os seres humanos pensam o desenvolvimento, é por meio da educação, pois é por meio dela que os diversos atores sociais adquirem grande parte dos seus valores e fatores norteadores de suas decisões.

Diversos outros autores advogam em favor do posicionamento de Lopes e Tenório (2006) quanto à importância estratégica da educação para a sustentabilidade e o desenvolvimento sustentável (SPRINGETT, 2005; GADOTTI, 2008; SAMUELSSON; KAGA, 2008; JICKLING, 2009; SARTORI; LATRÔNICO; CAMPOS, 2014; GRISWOLD, 2017; DUBEY; GUNASEKARAN; DESHPANDE, 2017).

Após ter sido defendida a importância da EPS e para o desenvolvimento sustentável, é relevante para os objetivos desse trabalho, diferenciá-la da educação convencional ou de conceitos similares, como a educação ambiental, bem como apresentar e debater as principais conceituações e caracterizações da EPS, como vem sendo nomeada.

Primeiramente, em relação à diferenciação entre a educação convencional e a EPS, temse, segundo Smith e Stevenson (2017), que - enquanto a primeira visa principalmente à formação de mão de obra, basicamente para alimentar as organizações que operam dentro do modo de produção capitalista, oferecendo para isso uma abordagem do conhecimento fragmentada, disciplinar e estreita, a fim de inviabilizar a visão do todo e, por conseguinte, fomentar o posicionamento acrítico dos indivíduos a respeito da realidade que estão colaborando para construir - a segunda, de acordo com Springett (2005), visa, além do conhecimento técnico/científico, desenvolver nos alunos, princípios e formas de ver que os habilitarão a serem questionadores das lógicas que norteiam o mundo que vivem.

Dessa forma, fica evidente que aqueles que operam dentro da lógica do capitalismo, tendo como único viés a dimensão financeira, são contrários à implementação de tal modelo educacional sustentável, e são adeptos do primeiro, pois dele dependem tanto a continuação de sua ideologia, quanto a manutenção de sua necessária mão de obra. Daí emerge uma das maiores dificuldades para a implementação desse novo modelo educacional.

É notória a distinção entre a educação ambiental e a EPS. A educação para a sustentabilidade é na verdade uma ampliação ao longo dos anos da educação ambiental. Ampliação no sentido de que, enquanto a educação ambiental foca de forma estreita a preservação do meio 
ambiente, a EPS alarga o seu escopo e busca integrar a preservação do meio ambiente às necessidades e desejos da sociedade, de forma a viabilizar o suprimento dessas necessidades no presente e no futuro. Nesse sentido, Jacobi et al. (2011) ainda acrescentam que,

\begin{abstract}
Na terminologia europeia, EE (Environmental Education, Educação Ambiental) é um conceito bastante distinto de ESD (Education for Sustainable Development, Educação para o Desenvolvimento Sustentável). Ambos representariam correntes educacionais focadas na questão ambiental; mas com o diferencial de que a ESD estaria comprometida com o empoderamento dos educandos a fim de que estes se revelem protagonistas nas ações e tomada de decisões, ao passo que a EE representaria uma visão mais estreita e instrumental fundamentada estritamente na divulgação de conhecimentos científicos e tendo em vista a mudança de comportamentos (JACOBI et al., 2011, p. 5).
\end{abstract}

Porém, no Brasil, as diversas legislações desenvolvidas a esse respeito não fazem diferença entre os dois tipos de educação, se referindo a uma abordagem educacional que segue os pressupostos e princípios da EPS, apesentada e discutida até aqui, entretanto a nomeando como educação ambiental (CARVALHO; BRUNSTEIN; GODOY, 2014).

Dessa forma, partindo desses dois debates iniciais, pode-se começar o esforço de conceituação da EPS no sentido de buscar dar substância e forma ao seu conteúdo. Assim sendo, parte-se da perspectiva de que a EPS é essencialmente um modelo educacional crítico, interdisciplinar e multidimensional. Crítico porque, segundo Springett (2005), visa possibilitar aos alunos algo mais que o desempenho técnico eficiente: a possibilidade de criticar as lógicas que tecem a realidade na qual estão inseridos; e interdisciplinar e multidimensional porque considera diversas dimensões, tais como, social, ambiental e econômica, nos seus processos de ensino-aprendizagem.

Partindo desses pressupostos iniciais, diversos outros autores complementam a sua conceituação e caracterização (GADOTTI, 2008; BENFICA, 2012; MELO, 2012; DUBEY; GUNASEKARAN; DESHPANDE, 2017; FELGENDREHER; LÖFGREN, 2017).

Para Dubey, Gunasekaran e Deshpande (2017), a EPS é um processo de ensino-aprendizagem transformador, que visa desenvolver nos alunos, novos saberes e lógicas, que irão possibilitar a estes, disporem de um mundo equilibrado, nas dimensões sociais, econômicas e ambientais, de forma que esses indivíduos possam usufruir dos privilégios da natureza, da prosperidade econômica e de uma sociedade harmônica, no seu presente e em seu futuro.

Ainda segundo Dubey, Gunasekaran e Deshpande (2017), de acordo com extensa revisão de literatura, e com os resultados de um criterioso estudo empírico realizado na Índia com 5 universidades exemplares, no que diz respeito a práticas de EPS, os pesquisadores afirmam que as políticas governamentais, a demanda do mercado, as pressões dos pares, os valores, a atitude, a pedagogia, os recursos, o comportamento e a promoção são os principais fatores que moldam a educação sustentável. Vale salientar que a maioria desses fatores influenciadores foi identificada na revisão de literatura desenvolvida pelos pesquisadores, porém, os fatores atitude, comportamento e promoção, foram identificados no estudo empírico nas universidades.

Reforçando a ideia defendida por Dubey, Gunasekaran e Deshpande (2017), de que a EPS é um processo capaz de transformar a visão de mundo dos alunos, Felgendreher e Löfgren (2017) acobertam que a EPS de fato pode causar modificações no conjunto de princípios e percepções morais que norteiam os processos de tomada de decisão dos indivíduos, mesmo que estes não sejam os únicos fatores influenciadores dessas decisões, existindo ainda outros mais, porém, a EPS não influencia os valores morais dos alunos de forma homogênea, mas sim de forma diferenciada, de acordo com as características de cada aluno. 
De acordo com Gadotti (2008) e Benfica (2012), a EPS objetiva a construção de um ambiente equilibrado e harmonioso, do qual todas as formas de vida possam desfrutar e coexistir. Percebe-se, inclusive, nessa conceituação dos autores, a preocupação não só com a sustentabilidade das sociedades humanas, mas também com a sustentabilidade de todas as formas de vida que habitam a Terra. Nesse sentido, e buscando teorizar sobre como a EPS deve ser, Gadotti (2008) afirma que

Educar para a sustentabilidade implica mudar o sistema, implica o respeito à vida, o cuidado
diário com o planeta e cuidado com toda a comunidade da vida, da qual a vida humana é um
capítulo. Isso significa compartilhar valores fundamentais, princípios éticos e conhecimentos
como respeito à terra e a toda a diversidade da vida; cuidar da comunidade da vida com
compreensão, compaixão e amor; construção de sociedades democráticas que sejam
justas, participativas, sustentáveis e pacíficas. A sustentabilidade é um conceito central de
um sistema educacional voltado para o futuro. (GADOTTI, 2008, p. 76 , grifo do autor).

Outro aspecto importante a ser incorporado ao entendimento sobre EPS é o de Melo (2012): no que se refere ao caráter interdisciplinar desse modelo educacional, para o autor, devido a essa característica, EPS não deve ser tratada como uma disciplina isolada, mas ser interligada às diversas outras disciplinas trabalhadas pelas instituições de ensino.

Nesse sentido, Palma, Alves e Silva (2013) seguem a mesma linha de pensamento que Melo (2012). Para eles, a EPS traz um grande desafio atrelado ao seu caráter interdisciplinar, que é o desenvolvimento pelos professores e pesquisadores de uma metodologia que torne possível a inserção da questão da sustentabilidade em todas as disciplinas, ou no maior número delas possível. E ainda acrescentam que essa metodologia faça parte do dia a dia pedagógico das instituições, independente do nível de ensino e da área de atuação, seja ela de educação infantil, ensino fundamental, médio ou universitário.

Melo (2012, p. 16) afirma que quando se trata da EPS "parte-se da premissa de que é necessário que os alunos ampliem sua visão de mundo, repensem seus próprios valores e sejam capazes de questionar práticas que fomentam a insustentabilidade e que podem não ser passíveis de simples soluções". É possível notar que as ideias do autor se coadunam com as ideias de Dubey, Gunasekaran e Deshpande (2017) e Felgendreher e Löfgren (2017), quanto ao entendimento de que a EPS é um processo capaz de transformar a visão de mundo dos alunos, reforçando ainda mais essa característica deste tipo de educação.

Embora elaborado no início da década de 1990, o conceito atribuído à educação ambiental, ou educação para a sustentabilidade, na preparação da ECO-92, também traz características importantes desse novo modelo educacional, como a questão da adequação às realidades regionais e ao contexto histórico, como pode ser visto no trecho a seguir: "devendo considerar as condições e estágios de cada país, região e comunidade, sob uma perspectiva histórica[...]" (BAGGIO; BARCELOS, 2008, p. 132).

Palma, Alves e Silva (2013) levantam outra característica que merece atenção no âmbito da composição de uma educação voltada para a sustentabilidade. De acordo com os autores, a EPS tanto pode ser desenvolvida em contextos formais como em informais. Ou seja, àqueles que aprendem sobre sustentabilidade tanto devem ser estimulados a desenvolver seus conhecimentos, habilidades, atitudes e competências dentro dos ambientes formais de ensino-aprendizagem, como também nos diversos ambientes informais de aprendizagem, os quais estejam disponíveis para esses indivíduos.

Lopes e Tenório (2006) defendem que além da educação, a ética também deve ser atrelada à sustentabilidade, de forma que, além das quatro dimensões propostas pelos autores para a sustentabilidade, a saber, a econômica, ambiental, social e educacional, eles propõem ainda, 
a adesão da ética à sustentabilidade e a EPS, propondo assim, a transformação do tetraedro da sustentabilidade em uma pirâmide.

Por meio dos conceitos e caracterizações apresentados e discutidos até aqui, é factível definir os princípios fundamentais norteadores da educação para a sustentabilidade. Dessa forma, o Quadro 01 apresenta a síntese desses princípios, a fim de nortear a implantação da EPS nos diversos níveis de ensino.

Quadro 01 - Síntese dos princípios fundamentais da EPS

\begin{tabular}{|c|c|c|}
\hline Autores/ano & Princípios & Descrição dos princípios \\
\hline $\begin{array}{l}\text { Springett (2005), } \\
\text { Stevenson (2017) e } \\
\text { Dubey, Gunasekaran } \\
\text { e Deshpande (2017) }\end{array}$ & $\begin{array}{l}\text { Rompimento com a educa- } \\
\text { ção convencional }\end{array}$ & $\begin{array}{l}\text { Enquanto a educação convencional visa apenas a } \\
\text { formação de mão de obra para alimentar as organi- } \\
\text { zações capitalistas, a EPS foca desenvolver nos alu- } \\
\text { nos, princípios e formas de ver que os habilitarão } \\
\text { a serem questionadores e críticos das lógicas que } \\
\text { norteiam o mundo que vivem. }\end{array}$ \\
\hline Jacobi et al., (2011) & $\begin{array}{c}\text { Diferenciação entre EA e } \\
\text { EPS }\end{array}$ & $\begin{array}{l}\text { Enquanto a educação ambiental foca de forma es- } \\
\text { treita a preservação do meio ambiente, a educação } \\
\text { para a sustentabilidade busca integrar a preserva- } \\
\text { ção do meio ambiente às necessidades e desejos da } \\
\text { sociedade. }\end{array}$ \\
\hline Springett (2005) & $\begin{array}{l}\text { Interdisciplinaridade e mul- } \\
\text { tidimensionalidade }\end{array}$ & $\begin{array}{l}\text { A EPS considera diversas dimensões, tais como, so- } \\
\text { cial, ambiental e econômica, nos seus processos de } \\
\text { ensino-aprendizagem. }\end{array}$ \\
\hline $\begin{array}{l}\text { Felgendreher e Löf- } \\
\text { gren (2017) }\end{array}$ & $\begin{array}{l}\text { Potencial transformador } \\
\text { individualizado }\end{array}$ & $\begin{array}{l}\text { Apesar da EPS ser capaz de transformar os valores } \\
\text { morais dos alunos, ela não o faz de forma homogê- } \\
\text { nea, mas sim de maneira diferenciada, de acordo } \\
\text { com as características de cada aluno. }\end{array}$ \\
\hline Gadotti (2008) & $\begin{array}{l}\text { Integração com o meio e } \\
\text { descentralização }\end{array}$ & $\begin{array}{l}\text { Por meio da EPS, os educandos devem se enxergar } \\
\text { apenas como mais uma parte interligada do meio } \\
\text { ambiente, e não como o centro. }\end{array}$ \\
\hline Melo (2012) & Transversalidade & $\begin{array}{l}\text { A EPS não deve ser tratada como uma disciplina iso- } \\
\text { lada, mas ser interligada às diversas outras discipli- } \\
\text { nas que são trabalhadas em uma instituição. }\end{array}$ \\
\hline $\begin{array}{l}\text { Palma, Alves e Silva } \\
\text { (2013) }\end{array}$ & Universalidade & $\begin{array}{l}\text { A EPS tanto pode ser desenvolvida em contextos } \\
\text { formais como em informais }\end{array}$ \\
\hline $\begin{array}{l}\text { Baggio e Barcelos } \\
(2008)\end{array}$ & $\begin{array}{c}\text { Contextualização geográfica } \\
\text {-histórica }\end{array}$ & $\begin{array}{l}\text { A EPS busca adequação às realidades regionais e ao } \\
\text { contexto histórico da sociedade na qual ela é de- } \\
\text { senvolvida. }\end{array}$ \\
\hline $\begin{array}{l}\text { Lopes e Tenório } \\
(2006)\end{array}$ & EPS com ética & $\begin{array}{l}\text { As ações de EPS devem sempre ser desenvolvidas } \\
\text { de forma a atrelar a ética nos processos de ensino } \\
\text {-aprendizagem. }\end{array}$ \\
\hline
\end{tabular}

\section{PROCEDIMENTOS METODOLÓGICOS: [...] NUM INS- TANTE IMAGINO (FABRÍCIO ET AL., 1983)}

A posição epistemológica utilizada nesta pesquisa foi a interpretativista. Essa abordagem pressupõe a compreensão do mundo por meio da interpretação do pesquisador (MERRIAM, 1998). A pesquisa tem enfoque qualitativo, o que pressupõe uma metodologia própria. Para Godoy (1995), a pesquisa qualitativa refere-se ao método de investigação científica que tem foco no caráter subjetivo, compreendendo as suas particularidades a partir das perspectivas dos participantes. Segundo Merriam (1998), o foco dos estudos qualitativos são a interpretação e significado.

O fenômeno estudado nessa pesquisa é a sustentabilidade, e o objeto de estudo são 
as concepções de sustentabilidade de alunos do ensino fundamental I e II de uma escola particular localizada na cidade de João Pessoa - PB. O levantamento foi efetuado junto aos alunos de uma escola particular, localizada na área sul da cidade de João Pessoa. A escola foi fundada em meados da década 1980 e surgiu com a intenção de inovar o método de ensino. Atualmente, a escola possui 300 alunos regularmente matriculados. Em geral, os alunos são provenientes de famílias com poder aquisitivo médio que, de acordo com a Secretaria de Assuntos Estratégicos (SAE) do Governo Federal, são aquelas que possuem renda familiar variando entre $R \$ 1.764,00$ e R\$ 4.076,00 (BRASIL, 2012). A instituição trabalha, além da pré-escola, com alunos do 1ㅇa ao 9 은 ano do ensino fundamental, foco deste estudo.

A coleta de dados foi realizada no período de julho a novembro de 2016. Neste ano, o tema gerador da escola foi "Nosso planeta, nossa casa", um trabalho voltado à EPS, por isso a escolha do local.

Fizeram parte da pesquisa 180 alunos de 7 a 14 anos de idade, do 2으, 3ㅇ e $5 \circ$ ano do ensino fundamental I e do 60 ao 9 o ano do ensino fundamental II. Ficaram de fora as turmas referentes ao 1 은 e 4 o ano, que estavam participando de outro estudo e, por sugestão da escola, foi preferido não incluí-los nesta pesquisa. Da totalidade dos participantes, 93 foram do gênero feminino e 87 do gênero masculino, totalizando $59,4 \%$ da população total da escola. Entretanto, foram analisadas aproximadamente $20 \%$ das imagens representativas sobre sustentabilidade, das quais foram escolhidas por sorteio aleatório. Neste tipo de amostra, a premissa é de que cada indivíduo da população estudada tenha a mesma chance de ser escolhido para compor a amostra representativa (PEREIRA, 2003).

Para coleta dos dados, num primeiro momento, foi realizada uma reunião de apresentação com a direção da escola. Foi exposto o objetivo da pesquisa e discutido como a mesma poderia ser desenvolvida. Após anuência da diretoria, realizou-se uma reunião com os professores de cada turma e foram definidas as datas e aulas para aplicação. Em decorrência do ensino fundamental I e II possuir horários de aulas diferentes, sendo o ensino fundamental I pela tarde e o Il pela manhã, a pesquisa foi realizada nos dois turnos.

A coleta de dados se deu por meio da realização de oficinas de desenhos com direcionamento temático. Foi solicitado aos alunos que fizessem um desenho sobre o tema Sustentabilidade. Nesse momento, comunicou-se que eles não se preocupassem com a habilidade em desenhar, mas sim em representar por meio das imagens o que vinha a mente, referente ao tema. Também foi informado que os desenhos não precisavam ser pintados com lápis de colorir, caso não desejassem pintar. Todos os alunos foram convidados a desenhar, mas nem todos terminaram ou entregaram seus desenhos. $O$ tempo dado para confecção foi de trinta minutos. Não houve discussão antecedente à sessão de desenho. Apenas foi apresentada a atividade: "Desenvolver um desenho do que vem a sua mente quando ouve a palavra Sustentabilidade". Após o tempo estipulado, os desenhos foram entregues para análise posterior dos dados. Estas análises se basearam além dos desenhos em falas obtidas durante o momento da criação destes.

Por meio da análise sócio-hermenêutica de materiais visuais (ROSE, 2001; SERRANO, 2008; SERRANO; ZURDO, 2012), procurou-se trazer, além do imediatismo sensorial que uma imagem provoca diferentemente de um texto escrito, aquilo que ela pode se conectar com o emocional (MIRZOEFF, 2003). Para tal, também se levou em consideração para as análises o gênero, a idade média e o nível de instrução dos alunos do 20 ao 9 ㅇ ano do ensino fundamental, excetuando-se o 1 ㅇ e o 4ㅇ ano que estavam envolvidas em outra pesquisa e por opção da escola não participaram.

Inicialmente, os 180 desenhos foram analisados e decidiu-se selecionar uma amostra significativa, já que boa parte dos desenhos apresentou elementos homogêneos. Como as turmas possuíam um número diferente de alunos matriculados, foram selecionados alguns desenhos de cada turma, em torno de $20 \%$. Na Tabela 1 podemos visualizar a quantidade de desenhos analisados e a quantidade de 
alunos matriculados, como também a divisão de gênero, sendo $M$ para masculino e $F$ para feminino. $A$ idade descrita foi identificada segundo a média das idades (IM) por ano dos alunos de cada turma.

Tabela 1. Distribuição de alunos por turmas do 20 ao 9 을 ano do Ensino Fundamental

\begin{tabular}{|c|c|c|c|c|c|c|c|c|c|c|c|c|c|c|}
\hline TURMAS & \multicolumn{2}{|c|}{$\begin{array}{l}\text { 20 ANO } \\
\text { IM: } 07\end{array}$} & \multicolumn{2}{|c|}{$\begin{array}{l}\text { 30 ANO } \\
\text { IM: } 08\end{array}$} & \multicolumn{2}{|c|}{$\begin{array}{l}\text { 5o ANO } \\
\text { IM: } 10\end{array}$} & \multicolumn{2}{|c|}{$\begin{array}{l}\text { 60 ANO } \\
\text { IM: } 11\end{array}$} & \multicolumn{2}{|c|}{$\begin{array}{l}\text { 70 ANO } \\
\text { IM: } 12\end{array}$} & \multicolumn{2}{|c|}{$\begin{array}{l}\text { 80 ANO } \\
\text { IM: } 13\end{array}$} & \multicolumn{2}{|c|}{$\begin{array}{l}\text { 9o ANO } \\
\text { IM: } 14\end{array}$} \\
\hline \multirow{2}{*}{ Gênero } & $M$ & $\mathbf{F}$ & $M$ & $\mathbf{F}$ & $M$ & $\mathbf{F}$ & $M$ & $\mathbf{F}$ & $\mathbf{M}$ & $\mathbf{F}$ & $M$ & $\mathbf{F}$ & $M$ & $\mathbf{F}$ \\
\hline & 09 & 17 & 08 & 09 & 16 & 10 & 14 & 17 & 15 & 15 & 09 & 14 & 16 & 11 \\
\hline Total & \multicolumn{2}{|c|}{26} & \multicolumn{2}{|c|}{17} & \multicolumn{2}{|c|}{26} & \multicolumn{2}{|c|}{31} & \multicolumn{2}{|c|}{30} & \multicolumn{2}{|c|}{23} & \multicolumn{2}{|c|}{27} \\
\hline Amostra (20\%) & \multicolumn{2}{|c|}{5,2} & \multicolumn{2}{|c|}{3,4} & \multicolumn{2}{|c|}{5,2} & \multicolumn{2}{|c|}{6,2} & \multicolumn{2}{|c|}{6,0} & \multicolumn{2}{|c|}{4,6} & \multicolumn{2}{|c|}{5,4} \\
\hline $\mathbf{N}^{\circ}$ desenho/turma & \multicolumn{2}{|c|}{5} & \multicolumn{2}{|c|}{3} & \multicolumn{2}{|c|}{5} & \multicolumn{2}{|c|}{6} & \multicolumn{2}{|c|}{6} & \multicolumn{2}{|c|}{5} & \multicolumn{2}{|c|}{5} \\
\hline \multicolumn{15}{|c|}{ MÉDIA DE DESENHOS SELECIONADOS POR TURMA = 5 DESENHOS } \\
\hline
\end{tabular}

Fonte: Elaboração própria (2017).

\section{IMAGENS REPRESENTATIVAS DO ENSINO FUNDA- MENTAL I E II: [...] VAI VOANDO, CONTORNANDO A IMENSA CURVA NORTE E SUL (FABRÍCIO ET AL., 1983)}

As imagens podem representar um tema, um argumento, um significado, ou mesmo algo e ainda tratar sobre algo. Pode ser que uma coisa seja o que aparece na imagem, o que se vê ou observa, concreto e objetivo, e noutra o que a imagem pode sugerir, ou aquilo sobre o que a imagem trata, abstrato e subjetivo (GASTAMINZA, 2001).

Entre os desenhos da turma do 20 ano do ensino fundamental I (IM: 07 anos), 4 continham elementos ligados ao ambiente natural, representados pela Figura 2 (a), e 1 desenho apresentava uma concepção distante da natureza (Figura 2 (b)), porém, ambos continham a representação de pessoas(s).

Figura 2. Desenho da concepção de uma aluna (a) e de um aluno (b) do $2^{\circ}$ ano do Ensino Fundamental I sobre sustentabilidade.

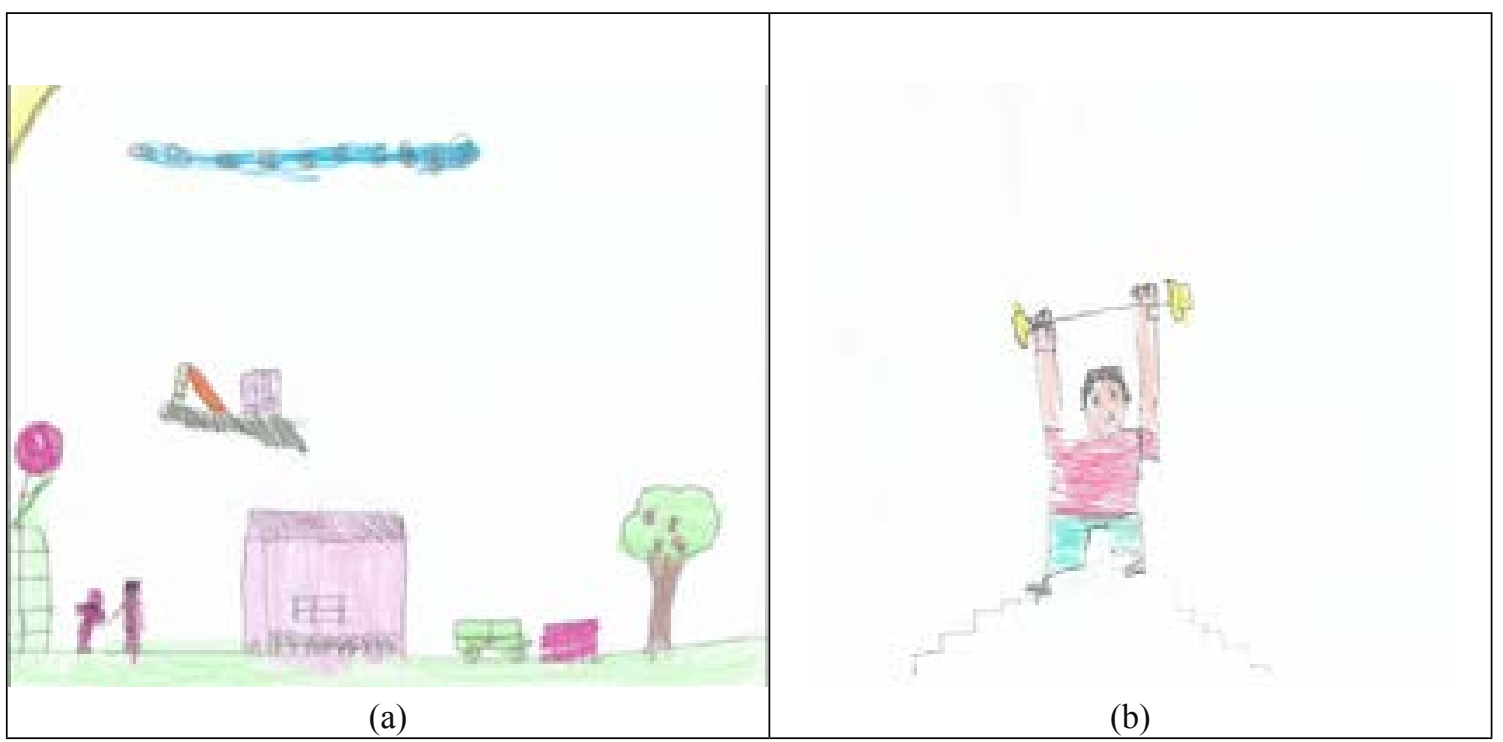

Fonte: Dados da pesquisa (2016). 
É importante salientar que a sustentabilidade está impressa de várias maneiras em ambas as figuras, e o que se pretende aqui é capturar as diversas concepções dos alunos acerca da sustentabilidade. Na Figura 2 (a), elementos como sol, céu, árvore e flor estão presentes no desenho, que causam a ideia de uma vida saudável e feliz. A imagem nos leva a um ambiente tranquilo e familiar, onde o homem vive em harmonia com o meio ambiente. A Figura 2 (b) apresenta como elemento principal o homem, no que parece levantar um halter no topo de um pódio, o que demonstra a força e o empenho do ser humano para alcançar um objetivo, e nestes termos, a sustentabilidade como um fim a ser atingida por meio de maneiras saudáveis e harmônicas. Tais imagens representativas convergem com a visão de Dovers e Handmer (1992) de que o desenvolvimento sustentável é a maneira de se alcançar a sustentabilidade, ou seja, uma via de se chegar à sustentabilidade (objetivo fim).

As Figuras 3 (a) e (b) retratam os desenhos elaborados pelo 3 으o ano do ensino fundamental I (IM:8 anos).

Figura 3. Desenho da concepção de uma aluna (a) e de um aluno (b) do 3o ano do Ensino Fundamental I sobre sustentabilidade.

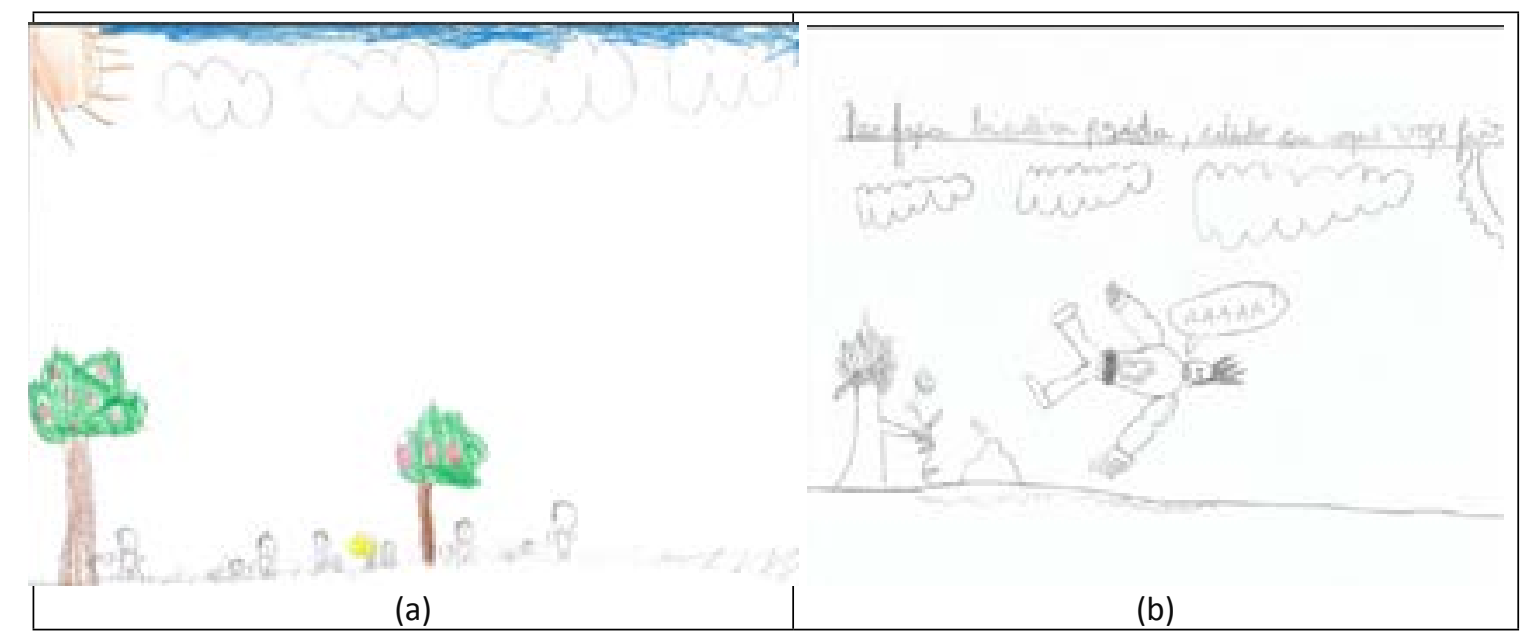

Fonte: Dados da pesquisa (2016)

Nos desenhos analisados dos alunos de 30 ano, as imagens remetiam à ideia da relação natureza-homem. Na Figura 3 (a), o aluno apresenta praticamente os mesmos elementos abordados pelos alunos do 2음 ano, como sol, céu, árvores frutíferas e pessoas. É possível notar na imagem a figura do homem, retratada por meio das várias pessoas cuidando da natureza, regando as árvores, plantando as flores. Esse cuidado demonstra a relação de responsabilidade que o homem deve manter com o meio ambiente, cultivando um clima harmonioso. A Figura 3 (b) também traz o homem na natureza, com a presença novamente dos elementos citados acima. Além disso, destaca a frase "Não faça brincadeira pesada, cuidado com o que você faz". É possível que uma ação negativa do homem, por exemplo lançar lixo no chão (como uma casca de banana), pode impactar em outros seres, além de causar dano no próprio ambiente. Na imagem visualizamos que o homem está levando uma queda ou escorregando em algo (alguma coisa lançada por outra pessoa, pois não se trata de um elemento da própria natureza).

A Figura 4 corresponde às imagens representativas da sustentabilidade do 50 ano, última turma do ensino fundamental I (IM: 10 anos). 


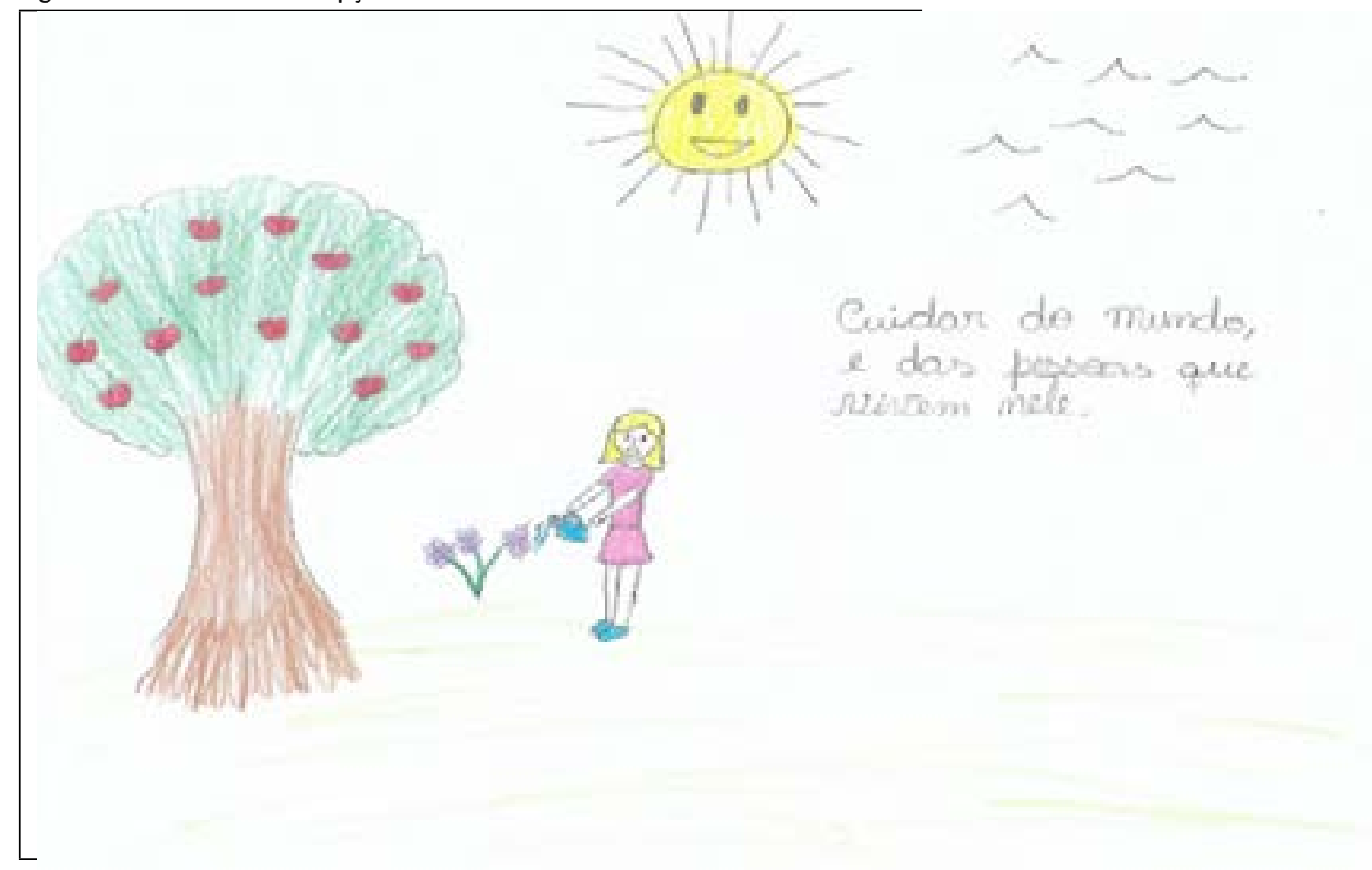

Fonte: Dados da pesquisa (2016).

A Figura 4 traz também a relação do homem com a natureza, retratada por meio do desenho de uma mulher cuidando das plantas, o que remete à consciência e à sensibilidade do homem em proteger e cuidar do ambiente. Para além das imagens, foi manifestado pela aluna que a sustentabilidade trata de "cuidar do mundo e das pessoas que vivem nele".

Observamos, pois, que tais elementos se fizeram presentes nos 5 desenhos analisados desta turma do 50 ano. A imagem de uma árvore, sol e céu, embora neste caso representado pela presença de pássaros voando, são elementos recorrentes nas turmas do ensino fundamental I. A presença de pessoas nos desenhos também evidencia a relação de respeito que as crianças imaginam do homem com o ambiente, numa convivência possível e positiva.

Observa-se que nenhum dos desenhos analisados referente ao ensino fundamental I abordaram elementos que remetessem a questões econômicas de maneira explícita, apesar de na Figura 2 (a), a aluna apresentar de forma singular elementos face ao desenvolvimento de um território (p. ex: moradia "casa" e transporte "carro"). As demais imagens representativas da sustentabilidade agregam elementos vinculados às concepções ambientais e, em menor grau, às sociais. Infere-se que, embora os desenhos estejam atrelados à natureza, nenhum deles retrata o assunto com imagens relacionadas ao desmatamento, falta de água ou poluição.

Em se tratando das imagens representativas do ensino fundamental II, crianças e adolescente entre 11 e 14 anos, alunos do 60 ao 9o ano, na turma do 60 ano (IM: 11 anos) foram analisados 6 desenhos. Devido à heterogeneidade das concepções, são apresentados 4 imagens (Figura 5 (a), (b), (c) e (d)). 
Figura 5. Desenho da concepção de um aluno (a) e de três alunas (b, c e d) do 6o ano do Ensino Fundamental II sobre sustentabilidade.

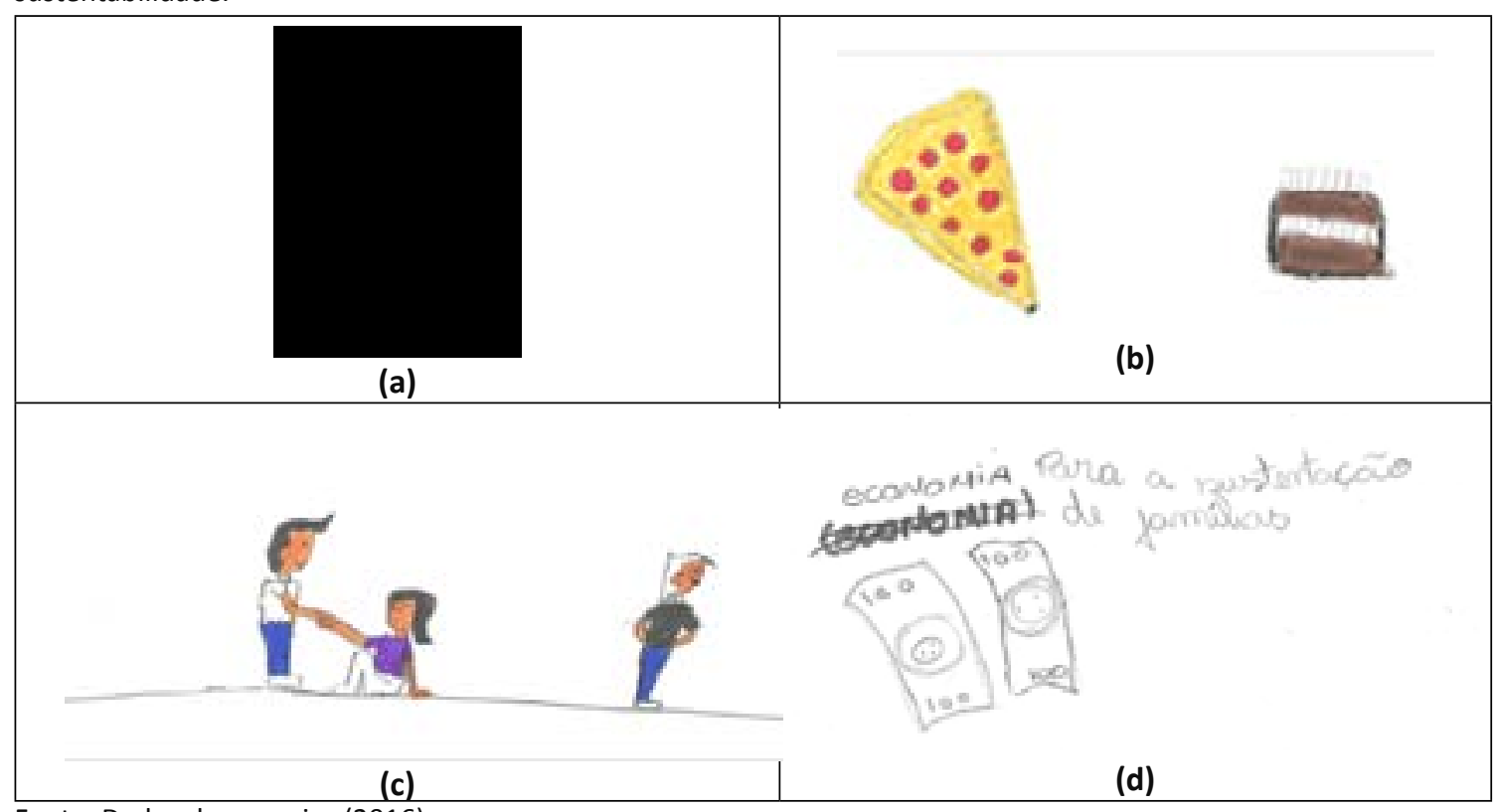

Fonte: Dados da pesquisa (2016).

Analisando os 4 desenhos é possível perceber a disparidade nas concepções das crianças e adolescentes. A Figura 5 (a) retrata o planeta dentro de uma casa, o que corrobora o tema gerador da escola trabalhado durante o ano de 2016, "Nosso planeta, nossa casa", ou seja, a ideia de que o planeta é o nosso lar, é o ambiente em que vivemos e não algo distante de nós mesmos, e que por isso precisamos cuidar dele.

Já na Figura 5 (b) temos a representação de uma fatia de pizza e um pote de chocolate, o que indica uma concepção ligada ao homem, afinal de contas, é preciso comer para se sustentar em pé. Entretanto, há que atentarmos para o fato das gerações atuais estarem imersas numa sociedade de consumo. Conforme o Relatório de Haya, destacado por Coelho (2012), tal documento ressalta que a sociedade de consumo é insustentável e se faz necessário investir em saúde e educação, no intuito de corrigir as injustiças sociais e evitar o aumento de uma dívida social que consumirá as gerações futuras.

A Figura 5 (c), por sua vez, está associada às relações sociais, representadas pela ajuda de um garoto a uma menina que está no chão. É possível ver na imagem que há outro garoto inerte à situação, o que muitas vezes ocorre em diversos momentos na vida real. Neste caso, se quer almejar a sustentabilidade social, na busca da igualdade entre todos, permitindo uma condição de vida melhor, reduzindo as desigualdades sociais, conforme atesta Montibeller-Filho (2008).

A Figura 5 (d) faz uma associação da sustentabilidade à concepção econômica, representada no desenho pelas cédulas de dinheiro e acompanhada da frase: "Economia para a sustentação de famílias". Segundo Sachs (1992), busca-se com a sustentabilidade econômica a segurança alimentar e a capacidade de modernização contínua dos instrumentos de produção para citar alguns critérios desta dimensão. Todavia, a articulação de critérios distintos de sustentabilidade em busca do eco-desenvolvimento somente será possível se fundamentada na harmonização de objetivos sociais, ambientais e econômicos, complementa Sachs (1992).

As Figuras 6 (a) e (b) correspondem ao 70 ano do ensino fundamental II (IM: 12 anos). 


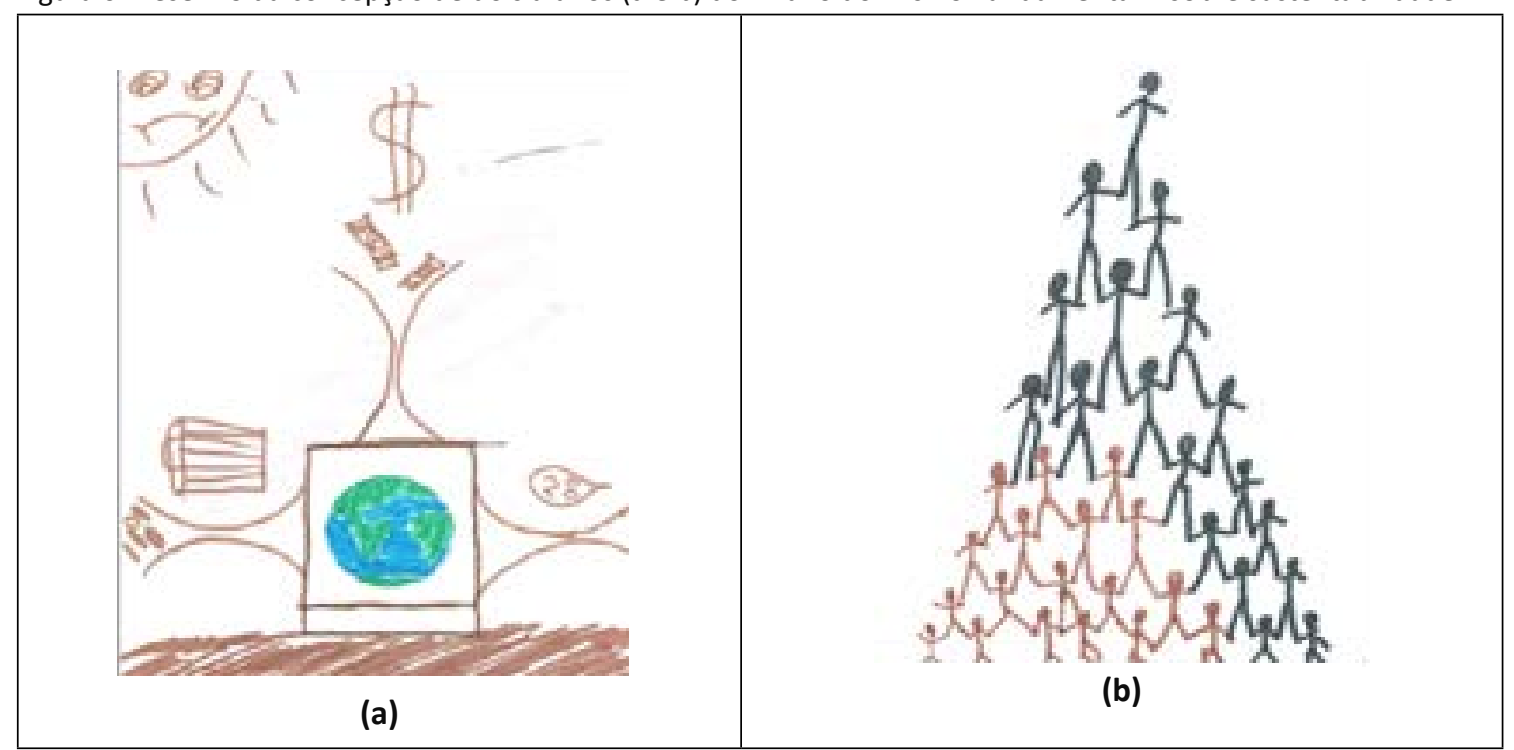

Fonte: Dados da pesquisa (2016).

Dos 5 desenhos analisados na turma do 7ㅇa ano, observamos a ausência de representações atreladas apenas à natureza ou ao ambiente natural, mas elementos que exprimem associações com o todo (pilares/dimensões da sustentabilidade). Isso nos remete ao conceito de Cavalcanti (1998, p. 165):

Sustentabilidade significa a possibilidade de se obterem continuamente condições iguais ou superiores de vida para um grupo de pessoas e seus sucessores em dado ecossistema. $\mathrm{O}$ conceito de sustentabilidade equivale à ideia de manutenção de nosso sistema de suporte da vida. Ele significa comportamento que procura obedecer às leis da natureza.

É possível verificar na Figura 6 (a) a presença do planeta em uma espécie de caixa receptora. Acima do planeta, vemos o sol com a expressão facial triste e um símbolo representando dinheiro com cédulas caindo em outra entrada da caixa. Do lado esquerdo da imagem há um balde de lixo e do outro lado (direito) há uma gota de água também com a expressão de tristeza. Ambas possuem entradas para o planeta. Abaixo, a cor marrom representa a terra, não há árvores, nem animais, nem pessoas. A atração visual nesta imagem representativa da sustentabilidade está concentrada em toda ela, apreendendo o olhar do leitor, uma vez que não emerge a figura humana.

Em contrapartida, a Figura 6 (b) representa uma pirâmide predominantemente composta de pessoas de diferentes raças e cores. Apresenta uma imagem equilibrada simetricamente, alicerçada numa base de sustentação formada por "bonecos" sem rostos, os quais se equilibram uns aos outros. Remete-nos à ideia de "um por todos e todos pelo todo - o ambiente". O desenho possui um convite à reflexão de que precisamos ser sustentáveis e nos faz mais uma vez pensar na nossa responsabilidade enquanto seres humanos. Tal imagem corrobora o pensamento de Silva, Reis e Amâncio (2014, p. 94), pois, segundo eles, a sustentabilidade se refere ao abandono de uma consciência individualista, em busca de uma coletiva: "A sustentabilidade estaria, então, ligada a uma noção de coletividade que vai muito além daquela presente nas outras formas de atuação organizacional com fins socioambientais, pois essas têm finalidade predominantemente individualista." Dessa forma, para os autores, uma das características e condições para sustentabilidade é o desenvolvimento de consciências coletivas, ou seja, o desapego com noções individualistas. 
Figura 7. Desenho da concepção de uma aluna (a) e de um aluno (b) do 8 o ano do Ensino Fundamental II sobre sustentabilidade.

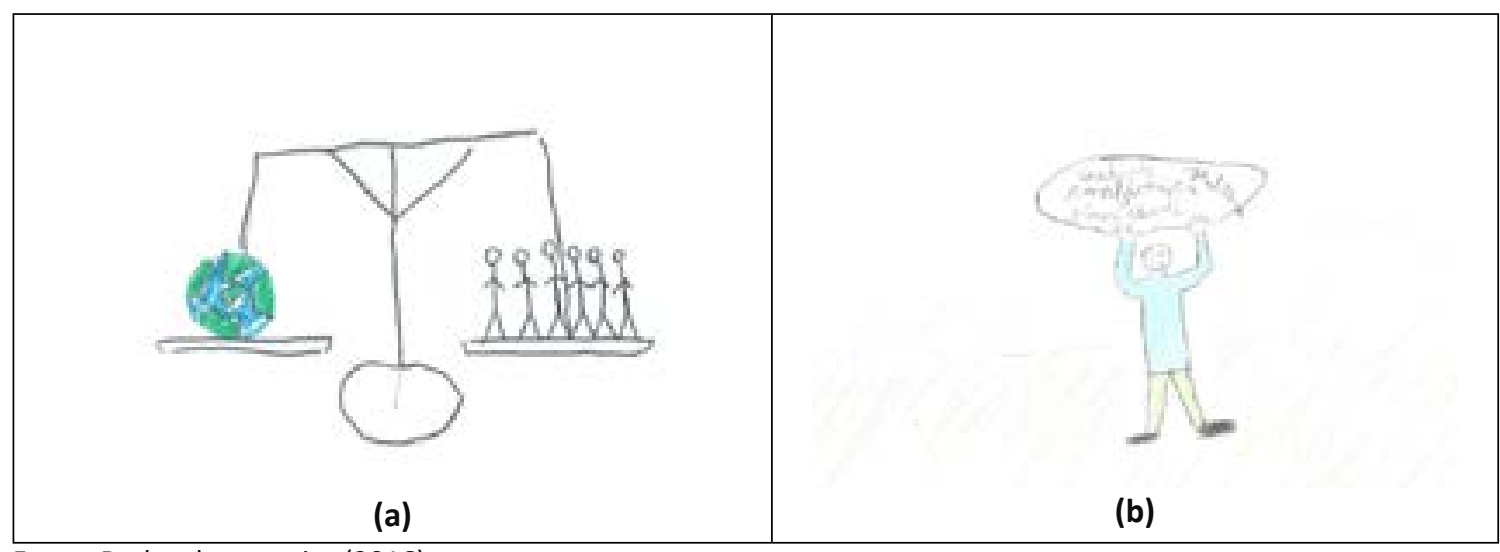

Fonte: Dados da pesquisa (2016).

Assim como nas figuras do 7ำ ano, as figuras do 8 o ano (Figura 7) apresentam concepções além da ambiental e social, ligadas à questão econômica, não identificadas nas turmas do ensino fundamental I.

A Figura 7 (a) representa os desenhos do 8 o ano (IM: 13 anos) em que traz uma balança, aparentemente em equilíbrio: de um lado está o planeta e do outro as pessoas, ou seja, um lado somente se sustenta dependendo do outro, em que a imagem expande-se do centro para as extremidades. Mais uma vez é relacionado à responsabilidade de indivíduo com o planeta. A Figura 7 (b) retrata a questão das relações sociais e os sentimentos envolvidos neste contexto. No centro da figura está um menino com uma placa escrita: "Amizade, gentileza, confiança e sinceridade", reforçando a pluralidade de entendimentos para com a sustentabilidade, conforme ressalta Lankoski (2016).

A Figura 8 traz as representações dos alunos do 9o ano (IM: 14 anos).

Figura 8. Desenho da concepção de dois alunos (a e b) do 9o ano do Ensino Fundamental II sobre sustentabilidade.

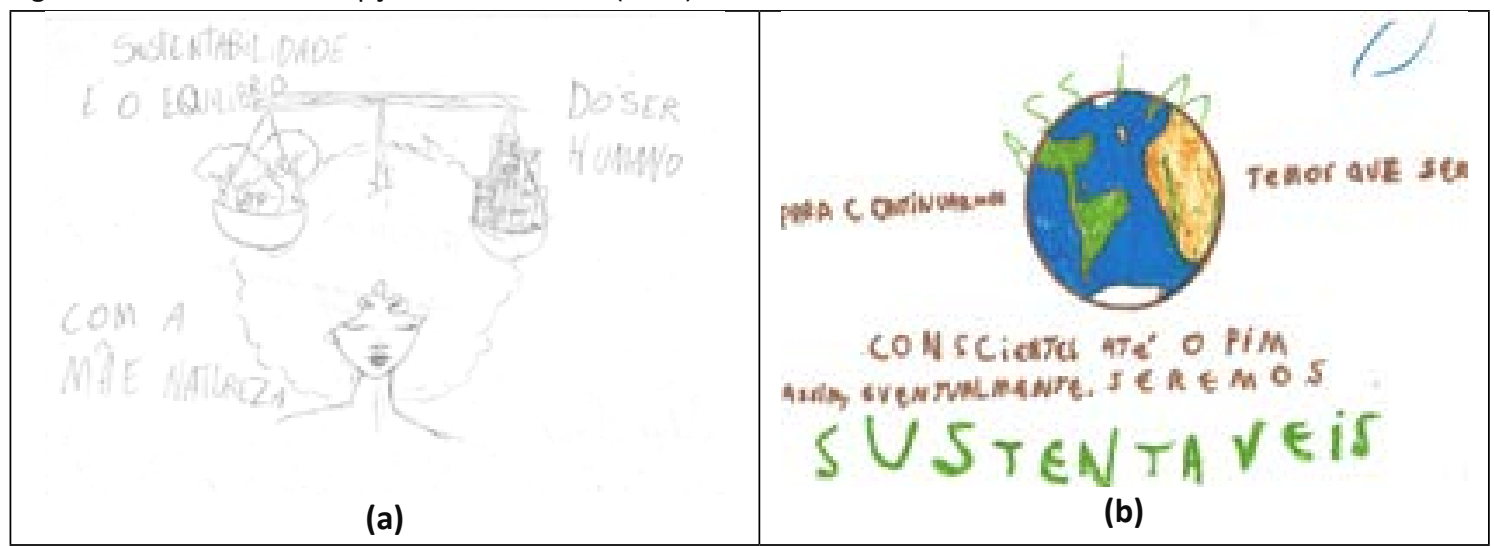

Fonte: Dados da pesquisa (2016).

A Figura 8 (a) mostra uma balança equilibrada na cabeça de uma mulher (remetendo à mãe natureza). De um lado, o ambiente natural, representado por um conjunto de árvores, e do outro, prédios, no que parece ser uma cidade um território em desenvolvimento ou a atuação de empresas. A balança está posicionada de forma como se saísse dos pensamentos da mãe natureza, isto é, como se tudo tivesse harmoniosamente em convívio. A frase "Sustentabilidade é o equilíbrio de ser humano com a mãe natureza" demonstra a consciência da relação do homem com o todo. 
Já na Figura 8 (b) vemos novamente a presença de um planeta bem colorido, predominando a cor azul (água), verde (natureza) e marrom (terra). Ao redor a frase "Para continuarmos assim [como ele retrata planeta], o temos que ser conscientes até o fim, assim, eventualmente seremos sustentáveis". É interessante notar que na turma do 9o ano há a presença de palavras escritas em quase todos os desenhos, as quais aparecem não da necessidade de explicar o desenho, mas de servirem como dicas para se conceber a sustentabilidade.

\section{CONCEPÇÃO DA SUSTENTABILIDADE NO ENSINO FUNDAMENTAL I E II: [...] ENTRE AS NUVENS VEM SUR- GINDO [...] TUDO EM VOLTA COLORINDO [...] BASTA IMAGINAR (FABRÍCIO ET AL., 1983)}

A figura 9 traz a categorização das imagens, distribuídas de acordo com as concepções ambientais, sociais e econômicas dos alunos. Destacamos que, em relação ao gênero, nesta etapa do desenvolvimento, não houve grandes diferenças no contexto geral.

Figura 9. Concepção da Sustentabilidade de alunos no ensino fundamental I e II.

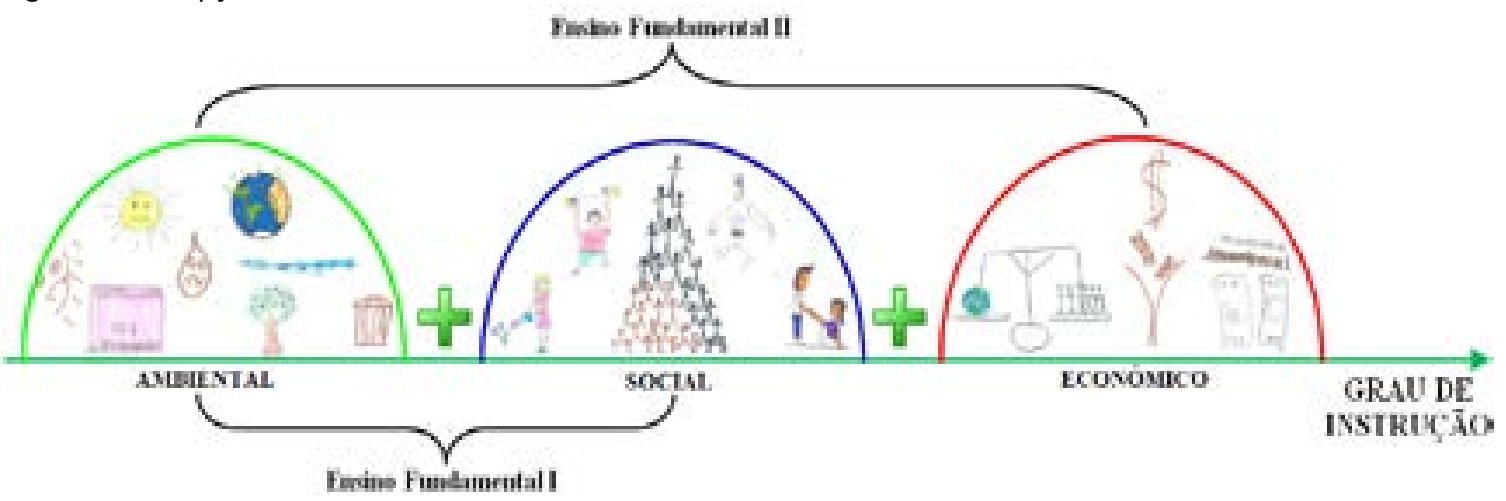

Fonte: Dados da pesquisa (2016).

O primeiro pilar ou dimensão está descrito à concepção ambiental, presente na maior parte dos desenhos referente ao ensino fundamental I. Esta concepção é representada pelos elementos como: sol, casa, água, árvore, céu, planeta, lixo e casa. Alguns desenhos abordaram além do ambiente natural a presença de pessoas, indicando a formação de uma concepção também social e da responsabilização do homem pelo ambiente (Figura 9).

O segundo pilar marca a presença da concepção voltada ao social, apresentada em menor grau no ensino fundamental I e de forma mais presente no ensino fundamental II. A responsabilização do homem pelo ambiente é um aspecto tratado pelas crianças e adolescentes de ambos os ciclos fundamentais, mas a abordagem das relações sociais é evidenciada em essência no ensino fundamental II, a partir do 60 ano. Os elementos representativos nesta dimensão são: homem (menino), mulher (menina), crianças e uma pirâmide de pessoas.

Já o terceiro pilar apresenta a concepção econômica, evidenciada por elementos como cédulas de dinheiro, cifrão e balança. Esta concepção é apresentada apenas pelos alunos do ensino fundamental II. É importante salientar que na maioria dos desenhos esta ideia se apresenta por vezes associada a um contexto geral e raramente sozinho. Destacamos que o gênero dos indivíduos investigados também não influenciou de maneira significativa a concepção nesta etapa do desenvolvimento. 
Percebe-se então que ao longo dos anos do ensino fundamental, as crianças e os adolescentes vão realizando associações mais completas no que tange à sustentabilidade. As concepções abarcam uma propriedade maior de elementos, deixando de focar apenas no ambiental, e convergindo para uma amplitude de pensamentos, o que permite às crianças e aos adolescentes realizarem interligações do que aprendem com os fatos reais (associando o ambiental, social e econômico). Isso provavelmente ocorre, além do promovido pelo próprio desenvolvimento da maturidade e pelo fato de acabar vivenciando e experimentando um maior número de situações que Ihes cobrem reflexão e posicionamento no seu dia a dia, graças ao trabalho desenvolvido pela escola no sentido da EPS. Entretanto, se faz necessário mais estudos a fim de averiguar as reais causas do alargamento dessas concepções.

\section{REFLEXÕES FINAIS: [...] DE UMA AMÉRICA A OUTRA CONSIGO PASSAR NUM SEGUNDO, GIRO UM SIMPLES COMPASSO E NUM CÍRCULO EU FAÇO O MUNDO (FA- BRÍCIO ET AL., 1983)}

A administração é a ciência que visa levar as organizações à consecução dos seus objetivos. Isto por meio da gestão eficiente e eficaz dos recursos disponíveis (ETZIONI, 1984). Por muitos séculos isso se deu em um ambiente em que pouco se pensava nos impactos da utilização não planejada desses recursos ao meio ambiente e à sociedade. Pporém, desde o fim do século $X X$, a comunidade mundial vem chegando a um consenso de que se faz urgente uma mudança drástica dessa forma de utilização não planejada e impensada dos recursos naturais por parte das organizações, tendo em vista a preservação desses recursos para suprir também as necessidades das futuras gerações, e assim promover o desenvolvimento sustentável (JACOBI, 2006; MACÊDO; OLIVEIRA, 2005; NASCIMENTO; CURI, 2013).

Entretanto, para que seja possível essa mudança na forma de gestão dos recursos naturais pelas organizações, antes se faz necessária, obviamente, uma mudança na postura da sociedade como um todo (JACOBI, 2006; MACÊDO; OLIVEIRA, 2005; NASCIMENTO; CURI, 2013), tendo em vista que as organizações são compostas por pessoas (adultos de hoje e adultos do amanhã).

Segundo Davis e Elliott (2014), as crianças são as maiores agentes de mudança que possuímos. Nesse sentindo, este estudo foi incitado a partir da necessidade de avaliar a concepção das crianças e adolescentes a respeito da sustentabilidade. Tendo a escola como uma unidade formadora destas concepções, o percurso desenvolvido neste estudo procurou demonstrar a formação destas crianças e adolescentes ao longo do ensino fundamental I e II. De acordo com os resultados obtidos, foi possível perceber que embora as concepções ainda apresentem elementos rasos no verdadeiro significado da sustentabilidade, o caminho vem sendo traçado e construído a partir da ingenuidade infanto-juvenil, com traços de pureza, ainda sem medo de ser feliz, e que tudo é possível, a depender de nós mesmos.

Há algumas décadas, o tema era tratado apenas por estudiosos, já na vida adulta, e, dependendo do contexto, muitas vezes era ignorado. Conceber a estes alunos a chance de desenvolver uma consciência crítica em relação ao assunto e assumir papeis em defesa da sustentabilidade é a chance de garantir um futuro melhor. Estas crianças e adolescentes serão futuros adultos, empresários, administradores de empresas, e precisam estar preparadas para os desafios que os aguardam.

A EPS se apresenta como uma opção para a formação de cidadãos mais conscientes e sensíveis à causa. $\mathrm{O}$ quanto antes o tema for abordado na infância, mais mudanças poderão ser 
provocadas nestes sujeitos e nas tomadas de decisões. É preciso salientar que a educação começa em casa, e que da mesma forma que a escola precisa remodelar a forma de educar os alunos, compatível com o mundo, os pais precisam também se apropriar dos assuntos, provavelmente ignorados na sua infância.

Precisamos, pois, promover esforços institucionais que abarquem os atores envolvidos no processo de ensino-aprendizagem - alunos, professores, funcionários e gestores - no sentido de reformular rotinas, estruturas e práticas profundamente enraizadas, aproveitando, portanto, a posição transformadora que a escola pode apresentar numa sociedade para influenciá-la efetivamente em prol da sustentabilidade.

Assim como uma aquarela, uma técnica de pintura que, quando diluída em água, transforma-se em tinta, podemos transformar toda uma sociedade, um mundo; mudar nossos hábitos e costumes para um mundo melhor. A canção Aquarela, escrita por Maurizio Fabrício, Guido Morra, Toquinho e Vinícius de Moraes, e lançada na década de 1980 no Brasil, nos faz refletir que um alguém (criança-menino-homem) pode colorir o mundo que imagina e deseja, como no trecho em destaque, mas uma simples ação ou atitude pode fazer perder o brilho, ou nos privar do seu uso e de sua beleza:

\author{
[...] Um menino caminha e caminhando chega no muro \\ E ali logo em frente a esperar pela gente o futuro está \\ E o futuro é uma astronave que tentamos pilotar \\ Não tem tempo nem piedade nem tem hora de chegar \\ Sem pedir licença muda nossa vida \\ Depois convida a rir ou chorar \\ Nessa estrada não nos cabe conhecer ou ver o que virá \\ O fim dela ninguém sabe bem ao certo onde vai dar \\ Vamos todos numa linda passarela \\ De uma aquarela que um dia enfim, descolorirá \\ Numa folha qualquer eu desenho um sol amarelo (que descolorirá) \\ E com cinco ou seis retas é fácil fazer um castelo (que descolorirá) \\ Giro um simples compasso e num círculo eu faço o mundo (que descolorirá) \\ (FABRíCIO et al., 1983. Grifo nosso)
}

O que observamos a partir dos materiais visuais de alunos do ensino fundamental I e II em João Pessoa-PB é que a EPS, como um instrumento junto ao processo de ensino-aprendizagem, pode promover tal transformação e ressignificação. E que se não tomarmos cuidado, boa parte da realidade um dia poderá perder a cor, ou melhor, descolorir, como tais versos da canção nos faz refletir. Talvez seja o segredo do futuro que nos reserva algo a partir da ação implacável do tempo. Precisamos construir o futuro, interagir com o meio de maneira a impactá-lo o mais positivamente possível, nos dando a liberdade e a criatividade de que, nas idas e vindas e nos contornos da vida ainda que de maneira lúdica, possamos sobreviver e dar a oportunidade de que outros também usufruam com qualidade os recursos disponíveis. Todavia, não nos deixemos levar pela poesia em si, já que o processo de mudança necessita de coragem para enfrentar o modelo dominante (lógica capitalista) presente em nossa sociedade. A quebra de paradigma requer novos hábitos e costumes, bem como tempo e tenacidade. Nesse sentido, investir nas futuras gerações é um caminho. 


\section{REFERÊNCIAS}

AZEVEDO, A.; GRAVE, P. S. A virtude epistêmica do administrador: primeiras explorações. In: COLÓQUIO INTERNACIONAL DE EPISTEMOLOGIA E SOCIOLOGIA DA CIÊNCIA DA ADMINISTRAÇÃO, 1. 2011, Florianópolis. Anais... Florianópolis: UFSC, 2011.

BAGGIO, A.; BARCELOS, V. Educação ambiental e complexidade: entre pensamentos e ações. Petrópolis: Vozes, 2008.

BARCELOS, V. Educação ambiental: sobre princípios, metodologias e atitudes. Rio de Janeiro: Vozes, 2008.

BERMEJO, R. Economía sostenible, principios, conceptos e instrumentos. Bilbao: Bakeaz, 2001.

BRASIL. Referencial curricular nacional para a Educação Infantil. Brasília: MEC/SEF, 1998.

. Institui as Diretrizes Curriculares Nacionais do Curso de Graduação em Administração, bacharelado, e dá outras providências. Resolução n.o 4, de 13 de julho de 2005. Disponível em: <http://portal.mec.gov.br/cne/arquivos/pdf/rces004_05.pdf>. Acesso em: 14 mai. 2017.

. Secretaria de Assuntos Estratégicos. Relatório de definição da classe média no Brasil.

2012. Disponível em:<http://www.sae.gov.br/documentos/publicacoes/relatorio-de-definicaoda-classe-media-no-brasil/>. Acesso em: 21 de set. 2018.

CAVALCANTI, C. Sustentabilidade da economia: paradigmas alternativos de realização econômica. In:___ (Org.). Desenvolvimento e natureza: estudos para uma sociedade sustentável. 2. ed. São Paulo: Cortez, 1998. p. 153-174.

COELHO, A. L. A. L. Construção do discurso da sustentabilidade: uma prática de análise sociológica do discurso no campo organizacional.2012. Tese (Doutorado em Administração e Turismo) Universidade do Vale do Itajaí, Biguaçu-SC.

D’ANGELO, M. J. Desenvolvimento de competências para a sustentabilidade: um estudo sobre a gestão de projetos societais sob a perspectiva de grupos. 2009. Dissertação (Mestrado em Administração de Empresas) - Universidade Presbiteriana Mackenzie, São Paulo.

DAVIS, J.; ELLIOTT, S. Research in early childhood education for sustainability: international perspectives and provocations. New York: Routledge, 2014. 337 p.

DERDYK, E.O desenho da figura humana. São Paulo: Scipione, 1990.

DERDYK, E. Formas de pensar o desenho: desenvolvimento do grafismo infantil. 3. ed. São Paulo: Scipione, 2004.

DOVERS, S. R.; HANDMER, J. W. Uncertainty, sustainability and change. Global Environmental Change, v. 2, n. 4,p. 262-276, 1992.

DUBEY, R.; GUNASEKARAN, A.; DESHPANDE, A. Building a comprehensive framework for sustainable education using case studies. Industrial and Commercial Training, v. 49, n. 1, p. 33-39, 2017.

ELKINGTON, J. Cannibals with forks: the triple botton line of 21st century business. Oxford: Capstone, 1997. 
ETZIONI, A. Organizações Modernas. São Paulo: Pioneira, 1984.

FABRíCIO, M.; MORRA, G.; TOQUINHO; MORAES, V. Aquarela [Gravada por Toquinho]. Em Aquarela [Disco Vinil]. São Paulo: Ariola, 1983.

FELGENDREHER, S.; LÖFGREN, A. Higher education for sustainability: can education affect moral perceptions? Environmental Education Research, 2017.

FREIRE, P. Educação como prática da liberdade. Rio de Janeiro: Paz e Terra, 1996.

GADOTTI, M. Educar para a sustentabilidade: uma contribuição à década da educação para o desenvolvimento sustentável. São Paulo: Instituto Paulo Freire, 2008. (Série Unifreire, v. 2).

GASTAMINZA. F. V. El análisis documental de la fotografía. 2001. Disponível em: <http:// pendientedemigracion.ucm.es/info/multidoc/prof/fvalle/artfot.htm>. Acesso em: 18 Fev. 2017.

GAVIÃO, L. O.; LIMA, G. B. A. Indicadores de sustentabilidade para a educação básica por modelagem fuzzy. Revista Eletrônica em Gestão, Educação e Tecnologia Ambiental, v. 19, n. 3 , p. 274-297, 2015.

GODOY, A. S. Introdução à pesquisa qualitativa e suas possibilidades. RAE, v. 35, n. 2, p. 57-63, 1995.

GRISWOLD, W. Creating sustainable societies: developing emerging professionals through transforming current mindsets. Studies in Continuing Education, v. 39, 2017.

HUCKLE, J. Realizing sustainability in changing times. In: HUCKLE, J.; STERLING, S. (Eds.). Education for Sustainability. Sterling-VA: Earthscan, 2014.

JACOBI, P. Educação ambiental, cidadania e sustentabilidade. Cadernos de Pesquisa, v. 118, n. 3, p. 189-205, 2003.

. Sustentabilidade Ambiental, Consumo e Cidadania. Ambiente e Sociedade, v. 9, n. 1, p. 183-186, 2006.

JACOBI, P. R.; GUERRA, A. F. S.; SULAIMAN, S. N.; NEPOMUCENO, T. Mudanças climáticas globais: a resposta da educação. Rev. Brasileira de Educação, v. 16, n. 46, p. 135-148, jan./abr. 2011.

JICKLING, B. Environmental education research: to what ends? Environmental Education Research, v. 15, n. 2, p. 209-216, 2009.

JONES, P.; SELBY, D.; STERLING, S. Sustaintability education: perspectives and practice across higher education. London: Earthscan, 2010.

JUNQUEIRA FILHO, G. A. Linguagens Geradoras: seleção e articulação de conteúdos em educação infantil. Porto Alegre: Mediação, 2005.

KLEIN, M. A psicanálise de crianças. Rio de Janeiro: Imago. (Original publicado em 1975), 1997.

LANKOSKI, L. Alternative conceptions of sustainability in business context. Journal of Cleaner Production, v. 139, p. 847-857, 2016.

LEÃO, A. C. Introdução à Administração Escolar. 2. ed. São Paulo: Companhia Editora Nacional, 1945. 
LEFF, E. Saber ambiental: sustentabilidade, racionalidade, complexidade, poder. Petrópolis: Vozes, 2001.

LOPES, U. M.; TENÓRIO, R. M. Trabalho, pesquisa e produção do conhecimento: paradigmas para a sociedade do conhecimento. 2006. Disponível em: <http://www.rp-bahia.com.br/biblioteca/ pdf/RobinsonTen\%F3rio.pdf>. Acesso em: 20 jun. 2017.

Educação como fundamento da sustentabilidade. Salvador: EDUFBA, 2011.

LOURENÇO FILHO, M. B. Organização e Administração Escolar: curso básico. 8. ed. Brasília. INEP/ MEC, 2007.

MACÊDO, K. B.; OLIVEIRA, A. A gestão ambiental nas organizações como nova variável estratégica. Rev. Psicol., Organ. Trab., v. 5, n. 1, p. 129-158, 2005.

MELO, H. S. Indicadores de sustentabilidade: uma análise em um sistema de coleta seletiva de material reciclável. 2008. Dissertação (Mestrado em Engenharia da Produção) - Universidade Federal da Paraíba, João Pessoa.

MELO, E. C. Educação para sustentabilidade e a experiência docente em cursos de administração.2012. Dissertação (Mestrado em Administração) - Universidade Presbiteriana Mackenzie, São Paulo.

MELO NETO, F. P.; BRENNAND, J. M. Empresas socialmente sustentáveis: o novo desafio da gestão moderna. Rio de Janeiro: Qualitymark, 2004.

MERRIAM S. B. Qualitative research and case study applications in education. San Francisco: Jossey-Bass, 1998.

MIKHAILOVA, I. Sustentabilidade: Evolução dos conceitos teóricos e os problemas da mensuração prática. Economia e Desenvolvimento, n. 16, p. 22-41, 2004.

MIRZOEFF, N. Una introducción a la cultura visual. Barcelona: Paidós, 2003.

MOCHIZUKI, Y.; FADEEVA, Z. Competências para o desenvolvimento sustentável e sustentabilidade importância e desafios para a ESD. IJSHE, v. 11, n. 4, p. 391-403, 2010.

MONTIBELLER-FILHO, G. O mito do desenvolvimento sustentável: meio ambiente e custos sociais no moderno sistema produtor de mercadorias. 3. ed. Florianópolis: UFSC, 2008.

MOREIRA, A. A. A. O espaço do desenho: A educação do educador. São Paulo: Edições Loyola, 1984.

MOURA, E. O. A textura da gestão escolar como prática sociomaterial. 2016. Dissertação (Mestrado em Administração) - Universidade Federal da Paraíba, João Pessoa.

NASCIMENTO, J. M. L.; CURI, R. C. A interface da responsabilidade social na gestão de recursos naturais. In: LIRA, W. S.; CÂNDIDO, G. A. (Orgs.). Gestão sustentável dos recursos naturais: uma abordagem participativa [online]. Campina Grande: EDUEPB, 2013. p. 173-192.

NEVES, V. F. A.; MUNFORD, D.; COUTINHO, F. A. C.; SOUTO, K. C. N. Infância e Escolarização: a inserção das crianças no ensino fundamental. Educação \& Realidade, v. 42, n. 1, p. 345-369, 2017. 
PALMA, L. C.; ALVES, N. B.; SILVA, T. N. Educação para a sustentabilidade: a construção de caminhos no Instituto Federal de Educação, Ciência e Tecnologia do Rio Grande do Sul (IFRS). RAM, v. 14, n. 3, p. 83-118, 2013.

PEREIRA, M. G. Epidemiologia: teoria e prática. 7. ed. Rio de Janeiro: Guanabara Koogan, 2003.

PIRES, L. M. F. S. A. A caminho de um ensino superior inclusivo? A experiência e percepção dos estudantes com deficiência - estudo de caso. 2007. Dissertação (Mestrado) - Faculdade de Motricidade Humana, Universidade Técnica de Lisboa, Lisboa, Portugal.

RIBEIRO, J. Q. Ensaio de uma teoria da Administração Escolar. São Paulo: Saraiva, 1986.

ROSE, G. Visual methodologies: an introduction to the interpretation of visual materials. 3. ed. London: Sage, 2001.

SACHS, I. Transition strategies for the 21st century. Nature and Resources, v. 28, n. 1, p. 4-17, 1992.

, I. Caminhos para o desenvolvimento sustentável. 4. ed. Rio de Janeiro: Garamond, 2002.

SAMUELSSON, I. P.; KAGA, Y. (Ed). The contribution of early childhood education to a sustainable society. Paris: UNESCO, 2008.

SARTORI, S.; LATRÔNICO, F.; CAMPOS, L. M. S. Sustentabilidade e desenvolvimento sustentável: uma taxonomia no campo da literatura. Ambiente \& Sociedade, v. 17, n. 1, p. 1-22, 2014.

SCHEIN, E. H. Psicologia Organizacional. Rio de Janeiro: Prentice-Hall do Brasil Ltda, 1982.

SERRANO, A. El análisis de materiales visuales en la investigación social: el caso de la publicidad. In GORDO, A. J.; SERRANO, A. (Coords.). Estrategias y prácticas cualitativas de investigación social. Madrid: Pearson Prentice Hall, 2008. p. 245-286.

SERRANO, A.; Zurdo, A. Investigación social con materiales visuales. In: MENÉNDEZ, M. A.; I. RODRÍGUEZ, S. (Coords.). Metodología de la investigación social: técnicas innovadoras y sus aplicaciones. Madrid: Síntesis, 2012. p. 217-250.

SILVA, S. S.; REIS, R. P.; AMÂNCIO, R. Conceitos atribuídos à sustentabilidade em organizações de diferentes setores. Revista de Ciências da Administração, v. 16, n. 40, p. 90-103, 2014.

SMITH, G. A.; STEVENSON, R. B. Sustaining education for sustainability in turbulent times. The Journal of Environmental Education, v. 48, n. 2, p. 79-95, 2017.

SPRINGETT, D. Education for sustainability in the business studies curriculum: a call for a critical agenda. Business Strategy and the Environment, v. 14, n. 3, p. 146-159, 2005.

TEIXEIRA, A. Que é administração escolar? Revista Brasileira de Estudos Pedagógicos, v. 36, n. 84, p. 84-89, 1961. 